\title{
Polymer Structural Effect on Photosensitivity and Thermal Stability of the Photosensitive Epoxy Resin Using the Photooxidation-induced Polycondensation Mechanism
}

\author{
Etsu Takeuchi ${ }^{\dagger}$ Yusuke Tajima ${ }^{\#+}$ and Kazuo Takeuchi ${ }^{\dagger,}$ "t \\ '; Graduate School of Science and Engineering, Saitama University, \\ 255 Shimo-Ohkubo, Urawa-shi, Saitama, 338-8570, JAPAN. \\ "'; Applied Laser Chemistry Laboratory, RIKEN (The Institute of Physical and Chemical Research), \\ 2-1 Hirosawa, Wako-shi, Saitama, 351-0198, JAPAN \\ Fax:81-48-462-4702, e-mail: etakeuti@postman.riken.go.jp
}

Keywords: photosensitivity, furan, novolac, epoxy resin

\section{Introduction}

Epoxy resin has unique properties for use in electronics devices, such as thermal stability, curing at a moderate temperature, and high adhesive strength. In addition, epoxy resin is much cheaper than the other thermally stable polymers such as polyimide. In recent years, a photosensitive epoxy resin, in which it is possible to make fine through-holes by photolithography, has been used as an interlayer dielectrics or cover resists in semiconductor devices and printed circuits such as the chip size package (CSP), ball grid allay (BGA), multi chip module (MCM), built-up printed circuit boards and so on[1]. However, photoreactive groups and sensitizers used for these photosensitive resins are thermally unstable, in general, and they cause a reduction in the heat resistance of the entire polymer system.

We have found that the UV-VIS irradiation of methyl 2-furoate in the presence of fullerene $\mathrm{C}_{60}$ and oxygen molecules yields a polycondensation resin precipitate, which is formed by the intermolecular dehydration induced by abstraction of the active hydrogen by the peroxy radical generated by the photo-oxidation of the furan ring (Photo-oxidation induced polycondensation; POP)[2]. Based on this mechanism, a polymer having a 2-substituted furan in its side chains can be crosslinked by UV-VIS irradiation in the presence of $\mathrm{C}_{60}$ in air. If this photocuring mechanism can be applied to a thermally stable polymer, we expect that the polycondensation crosslinking will contribute to an increase in their thermostability after the UV-VIS irradiation. Moreover, the high thermal stability of $\mathrm{C}_{60}$ as a photosensitizer should increase the high temperature tolerance. Consequently, the POP mechanism is expected to afford a new photosensitive resin having high thermal stability $[3,4]$. In the previous paper[5], we reported the development of a new photosensitive epoxy resin system based on the POP mechanism, consisting of furan-substituted novolac, epoxy resin and fullerene with amine as a curing agent. It produced a fine photolithographic pattern and high thermal stability. But its photosensitivity and thermal stability are still insufficient for the practical use.

In the present paper, we describe the preparation of three novolac resins having furan rings attached through different units. First, in order to improve the photosensitivity of the POP epoxy resin system, we synthesized furan-substituted novolac to which the furan ring is attached via a methylene (I) or carbonyl (II) unit. We expect novolac II to have a better reactivity to the furan ring than I. Second, to improve the thermal stability, we synthesized novolac with the furan ring attached to the novolac directly or through a spacer. The furan-substituted novolac III has an advantage in that it can be prepared readily by using commercially available materials such as furoyl chloride. Moreover, we 


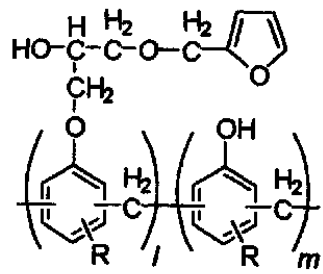

I

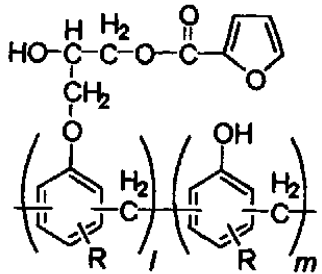

II

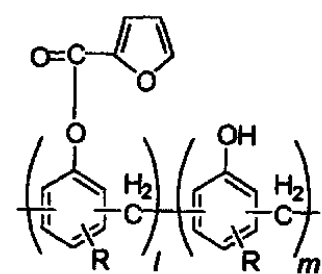

III expect novolac without a spacer III to have better thermal stability than those having a spacer (I, II) because the aliphatic spacer in I and II may decompose easily in high temperature. We evaluated the influence of these molecular structures on photosensitivity and thermal stability.

\section{Experimental}

2.1 Preparation of furan-substituted novolac

2.1.1 furfuryl ether type (I)

A mixture of $9.361 \mathrm{~g}$ of furfuryl glycidyl ether (FGE, Aldrich Chemicals Inc.) and $19.97 \mathrm{~g}$ of $67.3 \%$ methyl ethyl ketone (MEK) solution of novolac (LF-4871, Dainippon Ink and Chemicals Inc.) was heated to its reflux temperature $\left(110^{\circ} \mathrm{C}\right)$ and $0.05 \mathrm{~g}$ of tri- $n$-butylamine was added dropwise. After 15 hours of heating, the reaction mixture was added dropwise into $1 \mathrm{~L}$ of water and the resin precipitated was collected and dried in vacuo at $50^{\circ} \mathrm{C}$ to give the furan-substituted novolac resin as a dark-brownish brittle solid in $85 \%$ yield. The spectroscopic data (IR and ${ }^{1} \mathrm{H}-\mathrm{NMR}$ ) were consistent with the given structure.

\subsection{2 furoic ester type (II)}

A mixture of $11.3 \mathrm{~g}$ of furoic acid, $5.7 \mathrm{~g}$ of sodium hydroxide and $30 \mathrm{~g}$ of distilled water was stirred with cooling at the room temperature until it became a homogeneous solution and then evaporated at $60^{\circ} \mathrm{C}$ for thour in vacuo to obtain a white solid. To this solid, $128.2 \mathrm{~g}$ of epichlorohydrine and 0.03 g of tetraethylammonium iodide were added and heated to its reflux temperature $\left(110^{\circ} \mathrm{C}\right)$. After 1 hour of heating, the precipitate was filtered off. To the filtrate $30 \mathrm{~mL}$ of toluene was added. The solution was washed twice with water, and the toluene was evaporated to give glycidyl furoate as a colorless liquid. The furan-substituted novolac resin was prepared by a procedure similar to 2.1 .1 but using $8.63 \mathrm{~g}$ of obtained glycidyl furoate instead of FGE. The resin obtained in $85 \%$ yield was a darkbrownish brittle solid and the spectroscopic data (IR and ${ }^{1} \mathrm{H}-\mathrm{NMR}$ ) were consistent with the given structure.

2.1.3 furoic ester type without spacer (III)

To a mixture of $19.9 \mathrm{~g}$ of MEK solution of novolac (LF-4871), $0.1 \mathrm{~g}$ of tetraethylammonium iodide and $7.0 \mathrm{~g}$ of MEK, $2.3 \mathrm{~g}$ of sodium hydroxide was added over a period of 5 minutes with cooling in an ice bath. After 1 hour of stirring $7.9 \mathrm{~g}$ of furoyl chloride was added over a period of 15 minutes. After 15 hours of stirring the reaction mixture was added dropwise into $1 \mathrm{~L}$ of water and the resin precipitated was collected and dried in vacuo at $50^{\circ} \mathrm{C}$ to give the furan-substituted novolac resin as a dark-brownish brittle solid in $90 \%$ yield. The spectroscopic data (IR and ${ }^{1} \mathrm{H}-\mathrm{NMR}$ ) were consistent with the given structure

\subsection{Photochemical studies}

A typical preparation of the resin film is as follows. To an $0.4 \mathrm{~mL}$ MEK solution of the furansubstituted novolac I $(0.36 \mathrm{~g})$ was added $0.083 \%$ $(w / w)$ toluene solution of the fullerene $\mathrm{C}_{60}$ (purity; $>99.98 \%$, Term Co., $4.2 \mathrm{~g}$ ) and MEK (1.4 g). A glass substrate was coated with this solution using a spin coater. The substrate was prebaked for 10 minutes at $50^{\circ} \mathrm{C}$ in a forced convection oven. The film thickness was determined to be $1.8 \mu \mathrm{m}$ using an Alpha-Step 500 surface profiler (KLA. Tencor Inc.). The resin film was exposed to ultraviolet light from a $500 \mathrm{~W}$ high-pressure mercury lamp at room temperature. The intensity at the exposed surface was measured with an USHIO UTI-150 UV light meter, and adjusted to $20 \mathrm{~mW} / \mathrm{cm}^{2}$ at $365 \mathrm{~nm}$. The film was developed by dipping in an aqueous solution (2.35\%) of tetramethylammonium hydroxide (TMAH) or a solution of TMAH in water/MEK $(85 / 15, \mathrm{v} / \mathrm{v})$ for 150 seconds, and then rinsed in water for 1 minute. The film thickness after development was also determined using the Alpha-Step 500 surface profiler.

\subsection{Thermal stability studies}

A typical preparation of the POP epoxy resin 
film is as follows. To a $0.4 \mathrm{~mL} 50 \%$ (w/w) MEK solution of I $(0.36 \mathrm{~g})$ were added the novolac type epoxy resin (N870, Dainippon Ink and Chemicals Inc., $0.25 \mathrm{~g}), 0.083 \%(\mathrm{w} / \mathrm{w})$ toluene solution of the fullerene $\mathrm{C}_{60}(4.2 \mathrm{~g})$, tri- $n$-butylamine $(0.05 \mathrm{~g})$ and MEK $(1.4 \mathrm{~g})$. A polyethylene telephtalate film substrate (MRX-100, Diafoil Hoechst Co., Ltd.) was coated with the polymer solutions prepared as described above. The coating was cured at up to $180^{\circ} \mathrm{C}$ for 1 hour. The thickness of the coating was determined to be $12 \mu \mathrm{m}$. The substrate was peeled off to obtain the cured epoxy resin film. A thermogravimetric analysis (TGA) of the film was performed using a TGA 2950 (TA Instruments Inc.) under nitrogen with $10^{\circ} \mathrm{C} /$ minute temperature ramps.

\section{Results and Discussion}

3.1 Synthesis of furan-substituted novolac

In order to utilize the photo-oxidation induced polycondensation (POP) reaction for a photosensitive epoxy resin system, furansubstituted novolac was prepared by the reaction of furfuryl glycidyl ether, glycidyl furoate or furoyl

Table I. Degree of furan-substitution of the furansubstituted novolac

\begin{tabular}{cc}
\hline Molecular structure & Degree of substitution* \\
\hline I & 0.50 \\
\hline I & 0.48 \\
\hline III & 0.45 \\
\hline
\end{tabular}

*...-estimated by ${ }^{1} \mathrm{H} \cdot \mathrm{NMR}$ sprctra

chloride to the phenolic hydroxyl group of novolac. The reaction was carried out at the 1:2 molar ratio of the furan-containing compound to the hydroxyl group in novolac. The degree of furan-substitution of the obtained polymer was estimated by the relative integral areas of the peaks at $6.4 \mathrm{ppm}$ (furan ring) and 6.5 7.5 ppm (benzene ring) in the ${ }^{1} \mathrm{H}-\mathrm{NMR}$ spectra. The degree of furan-substitution of the obtained novolac is summarized in Table $I$.
Table I shows that the degree of furan-substitution is in good agreement with the feed molar ratio. These results indicate that both the reaction of the glycidyl group and that of the acyl chloride group to novolac stoichiometrically occur to give polymers having both furan moiety and phenolic hydroxyl group. The remaining phenolic hydroxyl units not only can afford solubility to the aqueous alkaline developer, but also have reactivity with epoxy groups during thermal curing to produce a crosslinked structure after the photolithographic procedure.

\subsection{Lithographic evaluation}

Films of the photosensitive resin consisting of the furan-substituted novolac I to III and fullerene $\mathrm{C}_{60}$ were prepared to evaluate their photosensitivity. We investigated the relation between the exposure dose and the remaining film thickness after development. The ratio of the remaining film thickness of the exposed area to that of the undeveloped area was defined as the normalized film thickness. The exposure dose $D_{0.5}$ is defined as $50 \%$ of the normalized thickness after development. $\mathrm{D}_{0.5}$, the developers used and the saturated normalized thickness after sufficient irradiation are summarized in Table II. From Table II, the saturated normalized thickness of the film using II is smaller than that using $I$. However, $D_{0.5}$ values of the films using I and II are very similar. The dissolution rate of II to the aqueous TMAH is higher $(2.5 \mu \mathrm{m} / \mathrm{sec}$.) than that of $I(0.5 \mu \mathrm{m} / \mathrm{sec})$. We believe that the higher solubility of II to TMAH readily leads to the dissolution of low molecular weight fraction which hampers sufficient cross linkage by exposure. This results in a reduction of the normalized thickness. We expect that when a more dilute aqueous solution of alkaline is used as a developer, the normalized film thickness of II may increase. From these results we conclude that the structural difference of the methylene and carbonyl groups has little effect on photosensitivity.

Table II. $\mathrm{D}_{0.5}$, Saturated normalized thickness and developer of the system of furan substituted novolac/ $\mathrm{C}_{60}$.

\begin{tabular}{|c|c|c|c|}
\hline $\begin{array}{c}\text { Structure } \\
\text { of novolac }\end{array}$ & $\mathrm{D}_{0.5}, \mathrm{~J} / \mathrm{cm}^{2}$ & $\begin{array}{c}\text { Saturated } \\
\text { normalized } \\
\text { thickness }\end{array}$ & Developer* \\
\hline I & 4.0 & 0.84 & $\mathrm{~A}$ \\
\hline II & 4.2 & 0.74 & $\mathrm{~A}$ \\
\hline III & 17 & 0.67 & $\mathrm{~B}$ \\
\hline
\end{tabular}

*... A: aqueous solution of TMAH.

B: water/MEK solution of TMAH 


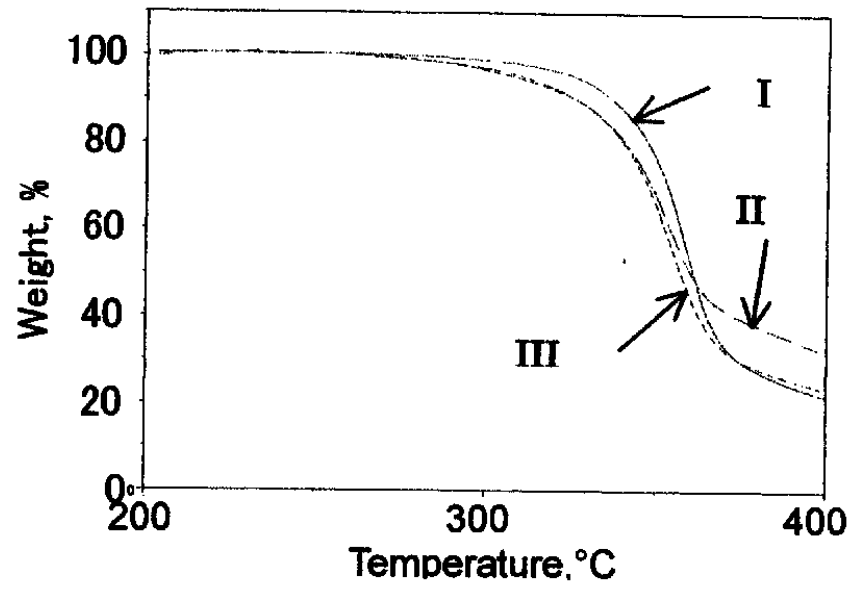

From Table II, $\mathrm{D}_{0.5}$ of the resin using III is higher than those using I and II, that is, III requires more exposure dose to become insoluble. This is explained as follows. The novolac III does not have a flexible 2-hydroxy-1,3-trimethylene unit between the furan moiety and the phenoxy group. This unit can increase the mobility of the furan moiety to enhance the formation of the crosslinked structure with another novolac molecule. From those results we conclude that introduction of a spacer unit between furan moiety and the phenoxy moiety of novolac is effective in enhancing its photosensitivity.

\subsection{Thermal stability of the resin film}

As described above, introduction of a spacer can enhance its photosensitivity. However, there is a concern that introduction of a flexible spacer that decomposes readily at high temperature may reduce the thermal stability of the resin. Therefore, we investigated the thermal stability of the resin system using novolac I to III. We studied thermal curing of the resin film consisting of the furansubstituted novolac, fullerene $\mathrm{C}_{60}$, epoxy resin and epoxy curing agent at a temperatures up to $180^{\circ} \mathrm{C}$ was carried out. The thermal stability of the resin films was estimated using a thermogravimetric analysis (TGA). Figure 1 shows the TGA curve of the resin after the thermal curing. The film using I showed the highest thermal stability with thermal degradation barely detectable below $300^{\circ} \mathrm{C}$. On the contrary, the film using III showed a slight weight loss above $200^{\circ} \mathrm{C}$, even though III does not have an aliphatic spacer. This result indicates that the flexible spacer has little effect on the thermal
Figure 1. Thermogravimetric curve of photosensitive epoxy resin after curing (Heating rate $=10^{\circ} \mathrm{C} / \mathrm{min}$. in nitrogen).

stability of the POP epoxy resin. This is somewhat different from what we expected. This may be due to the formation of different crosslinked structures in I, II and III. More detailed studies on the thermal properties of the POP epoxy resin system are now in progress.

\section{Conclusion}

We have prepared three furan-substituted novolac having different molecular structures and investigated the photosensitivity and the thermal stability of the POP resin system using them. Introduction of a 2-hydroxy-1,3-trimethylene unit between the furan ring and the phenoxy moiety of novolac is effective in enhancing its photosensitivity. In addition, the spacer has little detrimental influence on the thermal stability of the POP epoxy resin. More detailed studies of the effect of the molecular structure on the photosensitivity and thermal properties of the POP epoxy resin system are now in progress.

\section{References}

1. T. Takahashi, Journal of Japan Institute of Electronics Package, 2, 430(1999).

2. Y. Tajima, Y. Tezuka, T. Ishii and $\mathrm{K}$. Takeuchi, Polym. J., 29, 1016(1997).

3. Y. Tajima, Y. Shigemitsu, H. Arai, W. He, E. Takeuchi and K. Takeuchi, J. Photopolym. Sci. Technol., 12(1), 125 (1999).

4. E. Takeuchi, Y. Tajima, Y. Shigemitsu, K. Takeuchi and T. Hosomi, J. Photopolym. Sci. Technol., 13(2), 351 (2000).

5. E. Takeuchi, Y. Tajima, Y. Shigemitsu and K. Takeuchi, Trans. Mater. Res. Soc. J, submitted. 